\title{
Circular economy tourist practices
}

Sørensen, Flemming; Bærenholdt, Jørgen Ole; Greve, Kim Andreas Gjetting Møller

Published in:

Current Issues in Tourism

DOI:

10.1080/13683500.2019.1706456

Publication date:

2020

Document Version

Peer reviewed version

Citation for published version (APA):

Sørensen, F., Bærenholdt, J. O., \& Greve, K. A. G. M. (2020). Circular economy tourist practices. Current Issues in Tourism, 23(22), 2762-2765. https://doi.org/10.1080/13683500.2019.1706456

\section{General rights}

Copyright and moral rights for the publications made accessible in the public portal are retained by the authors and/or other copyright owners and it is a condition of accessing publications that users recognise and abide by the legal requirements associated with these rights.

- Users may download and print one copy of any publication from the public portal for the purpose of private study or research.

- You may not further distribute the material or use it for any profit-making activity or commercial gain.

- You may freely distribute the URL identifying the publication in the public portal.

Take down policy

If you believe that this document breaches copyright please contact rucforsk@kb.dk providing details, and we will remove access to the work immediately and investigate your claim. 


\section{Circular Economy Tourist Practices}

This research letter presents the findings of a Delphi study on the possible future development of circular economy principles in tourism. In contrast to the few existing circular economy studies in tourism research, which focuses on how companies may apply circular economy production principles, the Delphi study presented here suggests how tourists' practices may support the development of a circular economy in tourism. Further, the findings indicate drivers, complexities, paradoxes and barriers for such practices' future development.

Keywords: circular economy, tourists. practice theory, Delphi study

\section{Introduction}

Circular economy (CE) research focuses primarily on how companies may apply CE production principles. Nevertheless, in tourism consumers are important (co-)producers of tourism experiences and play an active and integrated role in the tourism system (Sørensen, Jensen, \& Hagedorn, 2018; Bærenholdt, Haldrup, Larsen, \& Urry, 2004). Thus, tourists may play a central role for developing circular economy principles in Tourism (CET). In this research letter, we report the findings of an exploratory Delphi study that aimed to identify potential tourist practices (Bispo, 2016) that support CET. Thus, the focus is on innovation not in products or production processes but in what people do (Pantzar \& Shove, 2010). The findings suggest current and future circular economy tourist practices (CETP) and indicate complexities, paradoxes and barriers for such practices' future development.

\section{Approaching circular economy tourist practices (CETP)}

CE refers to a restorative economy based on renewable energy and non-toxic renewable resources. It aims to limit waste by recycling products, components and resources and by keeping products, components and resources in use for longer (Macarthur, 2013). 
Tourism has traditionally been based on a 'take-make-dispose' logic (Fusco Girard \& Nocca, 2017; Manniche, Larsen, Broegaard, \& Holland, 2017), leaving environmental impacts because it implies travel, often relies on cheap and easily accessible resources, leaves solid waste and wastewater, and causes other environmental problems (Manniche et al., 2017). Developing a CE system in tourism is intricate because tourism involves different interdependent, complementary and competing sectors and mostly relates to hedonist consumption.

Because tourists are themselves producers of travel experiences, they may, through their practices, be a force in the development of CET. Practices are a temporally developing and spatially dispersed nexus of behaviours including practical activities, performances, representations and talk (Warde, 2005). They are routinized ways in which bodies are moved, objects handled, subjects treated, things described and the world understood (Reckwitz, 2002, p. 250). Pantzar \& Shove (2010) suggest how material (e.g. things), skill (e.g. bodily knowledge or competence), and image (e.g. mental activities, symbolic meaning) frame practice when integrated.

This provides a framework for understanding tourist practices and their development. In tourism, material includes goods, services, places, people, culture, etc. that tourists engage with. Skill (or competence or knowledge) refers to know-what and know-how applied in different tourist settings. Image (or meaning) may concern symbols and images of different tourist products, services, holiday types, destinations and experiences. Following Pantzar and Shove (2010), tourist practices result from the integration of these elements, and new practices evolve when they change and integrate in new ways. For example, traditional cycling holiday practices require cycles, tents, maps, etc. (material), cycling and map reading competences (skills), and appreciation of muscle-based slow travel (image). New E-bike holidays result from changes of the 
elements (battery driven bicycles, moderated cycling skills, another appreciation of moving/being moved). In a tourist practice analysis, the focus can be on 1) single practices related to specific services or products, for example, cycling or 2) bundles of practices making up tourist holidays, for example: cycling, reading maps, setting up tents, sleeping, etc. While companies (and other actors) are also important for developing elements supporting tourists' practices, CETP only happens when tourists integrate elements in common or novel ways.

\section{Method}

To identify potential CETP, a Delphi study was carried out to retrieve expert opinions regarding 1) characteristics of existing and 2) future CETP, and 3) barriers and 4) potential drivers for such practices. The study involved a panel of tourism experts including industry representatives, organizational leaders, and opinion makers (e.g. travel bloggers). They originated from Denmark, however, they were asked their opinions about CETP in general and not specifically about Danish tourism.

Delphi studies in tourism research aim to forecast trends and market conditions. Earlier studies have involved between six and 900 respondents/experts, with the lower quartile of studies involving 15 or fewer experts, and one to four rounds of interviews (two rounds being the most common) (Lin \& Song, 2015). Compared with these studies, our Delphi study had a typical design. It consisted of two rounds. Fifty relevant experts were initially identified and contacted. Of these, 32 agreed to participate, of whom 18 answered round one and 13 round two.

In round one, respondents were introduced to the concept of CETP, and openended answers were collected about the four themes. The answers were condensed into lists of different categories for each of the four themes. In round two, the same experts were asked to select the five most important current trends, future trends, barriers and 
drivers presented in the lists. Comments and opinions about CETP and about the developed lists were also solicited to confirm that the developed categories were accepted by respondents.

\section{Findings}

First, the experts' answers in round one of the Delphi study were highly varied. Some referred to various bundled tourism practices; for example, particular holiday types such as nature tourism, active holidays (e.g. cycling and hiking), and staycation. Others suggested single practices related to using specific products, such as $\mathrm{CO}^{2}$-neutral accommodation and sharing platforms, and other less specific practices such as renting instead of owning equipment and waste handling.

Second, there was no sign of consensus in any of the themes. In the second round, none of the categories in the lists were chosen as one of the five most important by all respondents. Nevertheless, the highest-ranked current trends included practices of using sharing platforms, and active (e.g. cycling and hiking) holidays, as well as staycation. With regard to the highest-ranked future practices, these included using more sustainable transport (e.g. trains instead of planes), using sharing platforms, and minimizing food waste.

Third, because tourist practices analytically consist of both single and bundled practices, a single CETP may not result in a bundled CETP. For example, the topranked current trend (and the second most important future trend), using sharing platforms (for example, Airbnb), leads to more air travel (by both landlords and renters). Thus, it does not (currently) per se result in bundled CETP. However, combined with other forms of transport such as trains (top-ranked future trend), bundled CETP may develop. 
Fourth, although themes and suggestions received identify current and future trends of tourist practices, most suggestions implicitly or explicitly imply a role also for supplier-side practices. For example, the use of sharing platforms and sustainable means of transport implies that someone supplies these services. The combined role of both tourists and other actors is also clear when looking at the suggested drivers and barriers for CETP. The highest-ranked drivers include tourists' developing conscience about sustainability issues in relation to tourism, optimization of energy systems in the industry, policy initiatives supporting train travel, and political framework conditions. The highest-ranked barriers include (low) price of air travel, lack of political initiatives supporting CET innovation, and increasing numbers of tourists globally for whom tourism is primarily a hedonistic activity. Thus, tourists, industry and government are all considered to cause both barriers and drivers.

Combined with the bundled nature of CETP, this means that CETP presents a high compound (Warde, 2013) complexity in that different actors together impact on and shape each other's practices. Thus, industry actors and policy-makers play important roles in providing CETP material (products/services/places), images (e.g. through marketing) and skills (e.g. knowledge of CETP), while tourists, through their practices and based on their images, skills and access to material, choose, learn and develop new practices. The bundled and compound nature of CETP means that supplier-side practices are important, but it also implies that focusing solely on how industry may develop CET production practices (the dominant approach) provides a one-sided and highly limited picture of the possible future development of CET.

All in all, in spite of a lack of clear consensus among the experts, a pattern emerges in which bundled practices of sharing and alternative means of transport (other 
than plane travel) are considered the more relevant trends in CETP, in addition to, and possibly combined with, different active holidays and minimization of food waste.

\section{Conclusion}

The Delphi study has indicated that there are numerous possibilities for developing CETP, single and bundled. However, the study also illustrated that important single CETP may not lead to bundled CETP. This is particularly important to realise in the case of popular sharing platforms, such as Airbnb, which must be bundled with other CETP, for example other types of transport than air travel as well as with resource and waste limiting practices. Furthermore, the study revealed a lack of consensus about relevant CETP and about how to develop them. This may be due to the newness of the topic, but it can also be due to experts being influenced by their different backgrounds, e.g. industry representatives may see other types of solutions than those put forth by the opinion makers. This may result in difficulties with defining future CET developments. The findings also indicate the compound nature of CETP and, thus, that neither the supplier side or public actors, nor the tourists must be ignored when researching and developing CET.

While the CETP solutions suggested in the study are not unattainable, paradoxically, suppliers' and tourists' integrations of images, material and skills presently result in continued growth of non-CETP involving, for example, long-haul flights, more holidays and shorter length of stays, and cruise ship tourism. Local development goals, policy regulations and business model innovations sustain this development and there is little evidence that technological innovations in the near future will make these types of tourist practices CET friendly. Nevertheless, according to the 
Delphi study, tourism providers may prepare themselves for a future of new practices that challenge current ones.

This study has initiated a discussion about the role of tourist practices in a circular economy and highlighted relevant paradoxes and questions relevant for future research. Though the low number of experts in the Delphi study, originating from one country, is a limitation, the study does suggest several relevant avenues for future research. These include research on issues related to the compound nature of CETP and the intertwined roles of tourists, private and public actors. They also include questions related to the development of bundled CETP, especially at a time when sharing economy platforms sustain more individually organised (short term) travel (by air). Overall, the study suggests that more research is needed about tourists' practices and tourism's intersection with circular economy, in order to facilitate a greater consensus about possible solutions and ways towards more environmentally sustainable tourism. Finally, tourism is both a local and a global activity, with local and global environmental impacts. Therefore, future compound and bundled CETP and research on such CETP must encompass this global-local nexus.

\section{References}

Bispo, M. D. S. (2016). Tourism as practice. Annals of Tourism Research, 61, 170-179.

Bærenholdt, J. O., Haldrup, M., Larsen, J., \& Urry, J. (2004). Performing tourist places, Aldershot: Ashgate.

Ellen MacArthur Foundation. (2013). Towards a circular economy. Ellen MacArthur Foundation..

Fusco Girard, L., \& Nocca, F. (2017). From linear to circular tourism. Aestimum,70, $51-74$.

Lin, V. S., \& Song, H. (2015). A review of Delphi forecasting research in tourism. Current Issues in Tourism, 18(12), 1099-1131. 
Manniche, J., Larsen, K. T., Broegaard, R. B., \& Holland, E. (2017). Destination: A circular tourism economy. A handbook for transitioning toward a circular economy within the tourism and hospitality sectors in the South Baltic Region. Nexø: Centre for Regional and Tourism Research,.

Pantzar, M., \& Shove, E. (2010). Understanding innovation in practice: A discussion of the production and re-production of Nordic walking. Technology Analysis and Strategic Management, 22(4), 447-461.

Reckwitz, A. (2002). Toward a theory of social practices: A development in culturalist theorizing. European Journal of Social Theory, 5(2), 243-263.

Sørensen, F., Jensen, J. F., \& Hagedorn, P. (2018). Co-creation of tourism place experiences. In M. Kozak \& N. Kozak (Eds.), Tourist behavior: An experiential perspective (pp. 1-18). Cham: Springer.

Warde, A. (2005). Consumption and theories of practice. Journal of Consumer Culture, 5(2), 131-153.

Warde, A. (2013). What sort of a practice is eating? In E. Shove \& N. Spurling (Eds.), Sustainable practices: Social theory and climate change (pp. 17-30). London: Routledge. 